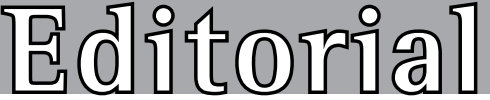

\section{Co-infecção tuberculose/HIV}

Tuberculosis/HIV co-infection

\section{Antônio Carlos Moreira Lemos}

A tuberculose (TB) é responsável por 1,6 milhão de mortes anualmente, e esta é uma história que se arrasta por séculos. Com o surgimento do HIV, a partir do início dos anos 80, houve uma mudança no perfil clínico e epidemiológico da TB. A co-infecção TB/HIV é responsável pelo aumento da incidência, da prevalência e da mortalidade por $\mathrm{TB}$, fato este que é bem mais acentuado no continente africano, onde acontece um terço dos casos de TB. ${ }^{(1)}$

Até 1993, distinguiam-se duas apresentações clínicas da co-infecção TB/HIV: a TB no paciente soropositivo para HIV sem AIDS e a TB associada a AIDS. ${ }^{(2)} A$ partir deste ano, a Organização Mundial de Saúde classificou a TB como uma condição definidora de AIDS nos infectados pelo HIV.(3) A contagem dos linfócitos CD4, que define o estágio de imunossupressão, é utilizado para comparar a apresentação clínico-radiológica. ${ }^{(4)}$ Assim, o ponto de corte da contagem de CD4 foi definido como 200 células $/ \mathrm{mm}^{3}$. Estudos têm demonstrado as seguintes apresentações observadas nas radiografias de tórax: apresentações compatíveis com TB primária evolutiva; apresentações compatíveis com TB pósprimária; TB miliar; alterações mínimas em até 5\% dos casos; e radiografia de tórax normal em até 14\% dos casos. Predominam a forma primária evolutiva e radiografia de tórax normal nos pacientes com CD4 $<200$ células $/ \mathrm{mm}^{3}$. A forma pós-primária acontece mais freqüentemente nos pacientes com CD4 > 200 células $/ \mathrm{mm}^{3} .^{(4)}$ Quanto mais profunda for à imunossupressão, menos usual é a apresentação na radiografia de tórax e maior é o envolvimento extrapulmonar com micobacteremia. Hemocultura positiva para Mycobacterium tuberculosis ocorre em até 49\% dos casos quando a contagem de CD4 é menor que 100 células $/ \mathrm{mm}^{3}{ }^{(5)}$

A associação desta co-infecção é sinérgica, interativa e recíproca, com significante impacto. Nesta situação, há um aumento da viremia plasmática com aprofundamento da imunossupressão e, por outro lado, ocorre um aumento do risco de desenvolver TB, variando de 37\% a 162\%, dependendo do estágio da imunossupressão, ${ }^{(2)}$ assim como acelerada progressão da doença, especialmente no contexto de uma exposição a bacilo multidroga resistente (MDR). ${ }^{(6)}$

Para o diagnóstico da TB, nesse contexto, são utilizados os mesmos meios diagnósticos que são usados normalmente: radiografia de tórax, baciloscopia e cultura do escarro. Deve-se acrescer a esses a cultura para micobactérias no sangue e na urina. Testes invasivos, tais como fibrobroncoscopia e biópsia de pleura e de gânglios, devem ser realizados quando indicados. Exames micobacteriológicos de aspirado hepático, medula óssea e líquor são reservados para condições específicas.

As micobactérias não tuberculosas, assim como os bacilos resistentes e MDRs são mais prevalentes nos pacientes soropositivos para HIV, havendo necessidade de se desenvolver métodos rápidos de diagnóstico e de determinação de sensibilidade às drogas. A amplificação do ácido nucléico, através da técnica de polymerase chain reaction, está indicada nos casos com baciloscopia do escarro positiva para confirmação rápida do diagnóstico de TB ou de outra micobactéria. Um teste rápido para detecção de TB-MDR, utilizando um método que avalia, através de um probe molecular, a detecção de mutações em três genes, já está disponível. 0 gene rpoB está associado à resistência a rifampicina; os genes kat $\mathrm{G}$ e inh $\mathrm{A}$ estão associados à resistência a isoniazida ( $\mathrm{INH})$. Em um estudo realizado em Cape Town, África do Sul, comparou-se este teste rápido com o método padrão, e os resultados mostraram sensibilidade e especificidade de 99\%, com resultados obtidos em dois dias. ${ }^{(7)}$ Este fato pode revolucionar o controle da TB-MDR.

0 tratamento para TB na co-infecção TB/HIV tem peculiaridades que merecem atenção, especificamente no uso concomitante de rifampicina e terapia anti-retroviral, quando, com freqüência, estas drogas não podem ser usadas conjuntamente. A terapia anti-retroviral aumenta a resposta ao teste purified protein derivative e reduz a incidência e a mortalidade devido à TB. 0 níveis de CD4 pré-tratamento e seis meses após o início do uso da terapia anti-retroviral são fatores determinantes. ${ }^{(8)}$

A África tem $11 \%$ da população mundial, mas responde por $29 \%$ dos casos de TB e $34 \%$ das mortes notificadas devido à TB em todo o mundo. As taxas são crescentes e passaram de 145/100.000 habitantes em 1990 para 342/100.000 habitantes em 2005. Ademais, a África responde por cerca de $85 \%$ dos casos da co-infecção TB/ HIV. Sabe-se que a TB-MDR é um problema mundial, mas sua prevalência na África está em nível inferior às observadas em alguns países, como China, Índia e Rússia. Um estudo em seis países demonstrou que a prevalência de 
TB-MDR variou de 0,7\% em Madagascar a 3,9\% em Ruanda. Em Botswana, nos virgens de tratamento, a prevalência de monorresistência foi de 10,4\% e de MDR, $0,8 \%$. Nos com tratamento prévio estas foram $22,8 \%$ e $10,4 \%$, respectivamente. ${ }^{(9)}$ Essas taxas são inferiores às observadas por nós em um estudo com 217 pacientes internados com TB em hospital de referência na Bahia, Brasil, sendo 15 desses pacientes positivos para HIV e 202 negativos (7\% de resistência primária, 43,1\% de resistência adquirida, 4,2\% de cepas MDR primária e 34,7\% de MDR adquirida). ${ }^{(10)}$ Extensively drug-resistant TB (XDR-TB, TB extensivamente resistente) foi avaliada em três países da África, mas só foi observada na África do Sul, onde 5,6\% dos casos de TB-MDR foram XDR-TB. Neste contexto, a associação TB/ HIV é fatal, como demonstrado no surto em Kuala Natal, África do Sul. ${ }^{(6)}$

Nesta edição do Jornal Brasileiro de Pneumologia, Nunes et al. analisaram 503 pacientes soropositivos para HIV com suspeita de co-infecção TB/ HIV em dois hospitais de Maputo, Moçambique. ${ }^{(11)}$ A baciloscopia e/ou cultura de amostras respiratórias foram realizadas em 447 pacientes. A cultura para micobactérias foi positiva em 320 casos. Nesse grupo, a baciloscopia foi positiva em 235. Apesar da identificação das espécies de micobactérias ter sido somente realizada em 277 cultivos, havendo a perda de 43 casos, ficou demonstrado que outras micobactérias são infreqüentes-apenas 3 casos, sendo 2 casos de $M$. avium intracellulare e um de $M$. simiae. Esses dados reforçam o que tem sido demonstrado na literatura médica e justificam o início do tratamento em pacientes com baciloscopia do escarro positiva, mesmo no contexto da co-infecção TB/HIV. A classificação radiológica dos casos apresentou um modelo predominante de TB primária evolutiva, com $67 \%$ de lesões intersticiais, $18 \%$ miliar, 30\% com linfonodos mediastinais e apenas $12 \%$ com lesões cavitárias, o que se justifica pela mediana de células CD4 de 134 células $/ \mathrm{mm}^{3}$. 0 teste de sensibilidade foi realizado em 258 casos, havendo a perda de 62 casos. A monorresistência primária foi de $9 \%$ nos pacientes sem tratamento prévio, passando para 13\% naqueles com tratamento prévio. A monorresistência à $1 \mathrm{NH}$ foi de $6 \%$ e $10 \%$, respectivamente, e à rifampicina, de $25 \%$ e $1 \%$, respectivamente. A prevalência de TB-MDR foi observada em $1 \%$ e $5 \%$, respectivamente, nos pacientes sem tratamento prévio e com tratamento prévio. Estes níveis de resistência são compativeis com os observados em outros países da África, mas inferiores aos observados em pacientes internados no Brasil. Esses dados demonstram um baixo nível de prevalência de TB-MDR nos pacientes sem tratamento prévio e, talvez, justifique um esquema de tratamento inicial com quatro drogas, com base na resistência primária a $1 \mathrm{NH}$ de $6 \%$. Acho que os autores contribuem para um melhor entendimento da TB em Moçambique, onde casos de TB são diagnosticados em estágio de imunossupressão avançada e com alto percentual de resistência primária à $1 \mathrm{NH}$. Os autores concluem que a estratégia do tratamento directly observed therapy, short-course deve ser reforçado e que deve haver uma preocupação com a quimioprofilaxia com $\mathrm{INH}$ no contexto da co-infecção TB/HIV.

\section{Antônio Carlos Moreira Lemos Doutor em Medicina, Chefe do Serviço de Pneumologia do Hospital das Clinicas e Professor Associado da Faculdade de Medicina da Universidade Federal da Bahia - FAMED/UFBA - Salvador, Bahia}

\section{Referências}

1. Chaisson RE, Martisson NA. Tuberculosis in Africa--combating an HIV-driven crisis. N Engl J Med. 2008; 358(11):1089-92.

2. Barnes PF, Bloch AB, Davidson PT, Snider DE Jr. Tuberculosis in patients with human immunodeficiency virus infection. $\mathrm{N}$ Engl J Med. 1991;324(23):1644-50.

3. Cantwell MF, Snider DE Jr, Cauthen GM, Onorato IM. Epidemiology of tuberculosis in the United States, 1985 through 1992. JAMA. 1994;272(7):535-9.

4. Greenberg SD, Frager D, Suster B, Walker S, Stavropoulos C, Rothpearl A. Active pulmonary tuberculosis in patients with AIDS: spectrum of radiographic findings (including a normal appearance). Radiology. 1994;193(1):115-9.

5. Jones BE, Young SM, Antoniskis D, Davidson PT, Kramer F, Barnes PF. Relationship of the manifestations of tuberculosis to CD4 cell counts in patients with human immunodeficiency virus infection. Am Rev Respir Dis. 1993;148(5):1292-7.

6. Gandhi NR, Moll A, Sturm AW, Pawinski R, Govender T, Lalloo $\mathrm{U}$, et al. Extensively drug-resistant tuberculosis as a cause of death in patients co-infected with tuberculosis and HIV in a rural area of South Africa. Lancet. 2006;368(9547):1575-80.

7. Barnard M, Albert H, Coetzee G, O’Brien R, Bosman ME. Rapid molecular screening for multidrug-resistant tuberculosis in a high-volume public health laboratory in South Africa. Am J Respir Crit Care Med. 2008;177(7):787-92. Epub 2008 Jan 17.

8. Lawn SD, Bekker LG, Wood R How effectively does HAART restore immune responses to Mycobacterium 
tuberculosis? Implications for tuberculosis control. AIDS. 2005;19(11):1113-24.

9. Nelson LJ, Talbot EA, Mwasekaga MJ, Ngirubiu PK, Mwansa RA, Notha M, et al. Antituberculosis drug resistance and anonymous HIV surveillance in tuberculosis patients in Botswana, 2002. Lancet. 2005;366(9484):488-90.

10. Matos ED, Lemos AC, Bittencourt C, Mesquita CL. Antituberculosis drug resistance in strains of Mycobacterium tuberculosis isolated from patients in a tertiary hospital in Bahia. Braz J Infect Dis. 2007;11(3):331-8.

11. Nunes EA, de Capitani EM, Coelho E, Panunto AC, Joaquim OA, Ramos MC. Mycobacterium tuberculosis and nontuberculous mycobacterial isolates among patients recently infected with HIV in Mozambique. J Bras Pneumol. 2008;34(10):822-828. 